\title{
Epidemiology, Clinical Presentations and In-Hospital Mortality of Venous Thromboembolism at the Douala General Hospital: A Cross-Sectional Study in Cameroon, Sub-Saharan Africa
}

\author{
Félicité Kamdem1,2*, Bertrand Hugo Mbatchou Ngahane1,2, Ba Hamadou3, \\ Agborbessong Mongyui' ${ }^{2}$, Marie Solange Doualla1,3, Ahmadou Musa Jingi, \\ Anastase Dzudie',3, Yves Monkam¹, Henri Ngote'1, Sidick Mouliom¹, Caroline Kenmegne1, \\ Jaff Kweban Fenkeu1, Romuald Hentchoya ${ }^{4}$, Albert Kana ${ }^{4}$, Aminata Coulibaly ${ }^{4}$, Henry Luma ${ }^{1,3}$ \\ ${ }^{1}$ Internal Medicine Service, Douala General Hospital, Douala, Cameroon \\ ${ }^{2}$ Faculty of Medicine and Pharmaceutical Sciences, University of Douala, Douala, Cameroon \\ ${ }^{3}$ Faculty of Medicine and Biomedical Sciences, University of Yaounde I, Yaounde, Cameroon \\ ${ }^{4}$ Intensive Care Unit, Douala General Hospital, Douala, Cameroon \\ Email: ^kamdem_djimegene@yahoo.fr, mbatchou.ngahane@yahoo.com,drhamadouba@yahoo.fr, mongyui_1@yahoo.fr, \\ marie.doualla@gmail.com, jingiahmadoumusa@yahoo.co.uk, aitdzudie@yahoo.fr, monakmy@yahoo.fr, ngoteroger@yahoo.fr, \\ masidick@yahoo.fr, jemmycaro@yahoo.fr, fkjaff@yahoo.fr, albertkanaa@yahoo.fr, albertkanaa@yahoo.fr, \\ aminatacoulibaly550@yahoo.fr, hnluma@yahoo.com
}

How to cite this paper: Kamdem, F., Ngahane, B.H.M., Hamadou, B., Mongyui, A., Doualla, M.S., Jingi, A.M., Dzudie, A., Monkam, Y., Ngote, H., Mouliom, S., Kenmegne, C., Fenkeu, J.K., Hentchoya, R., Kana, A., Coulibaly, A. and Luma, H. (2018) Epidemiology, Clinical Presentations and In-Hospital Mortality of Venous Thromboembolism at the Douala General Hospital: A Cross-Sectional Study in Cameroon, Sub-Saharan Africa. World Journal of Cardiovascular Diseases, 8, 123-132. https://doi.org/10.4236/wjcd.2018.82012

Received: December 24, 2017 Accepted: February 8, 2018 Published: February 11, 2018

\begin{abstract}
Background: Venous thromboembolism (VTE) is a major cause of morbidity and mortality worldwide. It is also the most common complication in hospitalized patients. Aims: To study the in-hospital prevalence of VTE, describe the socio-demographic characteristics of patients, determine the frequency of risk factors, describe the clinical presentations, and determine the short term outcome of VTE in hospitalized patients in a low-income tertiary hospital setting. Methods: We carried out a cross-sectional descriptive retrospective study over a period of 6 years and 4 months (January 2008 to April 2014) in the Douala General Hospital-Cameroon. Patients were cases of confirmed venous thromboembolic disease (VTE). Results: A total of 78 case files were retained for this study, giving an in-hospital prevalence of 4.4 per 1000 admissions. There were 42 (53.8\%) males and 36 (46.1\%) females. Their ages ranged from 18 to 89 years (median: 53 years, [IQR: $40-61]$ ). There were $37(47.4 \%)$ cases of Deep Vein Thrombosis (DVT), 31 (39.7\%) cases of Pulmonary Embolism (PE), and $10(12.8 \%)$ cases of PE associated with DVT (12.8\%). The main risk
\end{abstract}


Copyright $\odot 2018$ by authors and Scientific Research Publishing Inc. This work is licensed under the Creative Commons Attribution International License (CC BY 4.0).

http://creativecommons.org/licenses/by/4.0/ factors were obesity (44.9\%), hypertension (37.2\%), immobility (20.5\%), and long-haul travel (17.9\%). The most frequent clinical presentations in PE were dyspnea (80.5\%) and chest pain (65.9\%). There were $8(10 \%)$ in-hospital deaths. Conclusion: About twelve cases of VTE are seen yearly at the DGH, with an in-hospital mortality of ten percent. Obesity and hypertension were the main risk factors, with dyspnea and chest pain being the main clinical manifestations in PE, and lower limb swelling the main symptom in DVT.

\section{Keywords}

Epidemiology, Clinical Presentation, Mortality, Venous Thromboembolism, Cameroon, Sub-Saharan Africa

\section{Introduction}

Venous thromboembolism (VTE) is a major cause of morbidity and mortality worldwide. It is also the most common complication in hospitalized patients in high income settings [1] [2]. Autopsy reports showed a prevalence of $2.9 \%$ to $3.8 \%$ [3] [4], with an in-hospital incidence of $0.1 \%$ in Nigeria [5]. Data on the epidemiology of VTE are scarce in sub-Saharan Africa (SSA), with an in-hospital prevalence of 7\% [6] [7] [8]. The yield for acute pulmonary embolism (PE) was $37.5 \%$ for suspected cases [9]. The pattern of the epidemiology of VTE in SSA is comparable to that reported in the Asian sub-continent [10]-[15]. Deep Vein Thrombosis (DVT) of the legs has been shown to be more frequent than PE. The incidence of VTE has been shown to increase with age [16]. Emergency surgical procedures have been shown to be associated with higher rates of VTE.

Data on the epidemiology of VTE are scarce in our setting. We carried out this cross-sectional descriptive study with the aim of reporting the epidemiology, main risk factors, clinical presentations and short term in-hospital outcome in patients with a diagnosis of VTE at the Douala General Hospital-Cameroon, a low-income setting in SSA.

\section{Methods}

Ethical statement: This study was approved by the institutional review board of the University of Douala, and the administration of the Douala General Hospital. This work was carried out in accordance with the Declarations of Helsinki. We report this work in accordance with the standards for reporting epidemiological studies (STROBE) guidelines.

Study Design and setting: We carried out a cross-sectional descriptive retrospective study at the Douala General Hospital (DGH). We recruited cases that were hospitalized in the internal medicine and the intensive care unit (ICU) of the hospital. The DGH is a tertiary health institution in Cameroon, central Africa sub-region. It serves as a teaching hospital of the University of Douala, and has a catchment population of about 3 million inhabitants. It is equipped with 2 
ultrasound machines, and a 16 barrette multi-detector CT scan.

Participants: We reviewed the medical files of cases of VTE hospitalized in the hospital between January 2008 and April 2016 (6 years and 4 months). We included in the study confirmed cases of VTE disease. Confirmed cases had either contrast enhanced CT scan of the lungs, and or venous ultrasound performed after the primary diagnosis. Those with incomplete medical records (no confirmatory test done) were excluded.

Variables and measures: For each patient, we collected the following data: Socio-demography (age and sex), origin (home, other wards, and other hospitals), hospitalization ward (internal medicine, ICU), risk factors of VTE (medical, surgical, and social), clinical presentations (pulmonary embolism, deep vein thrombosis of the leg), electrocardiographic presentation, location of thrombus on vascular ultrasound (proximal, distal, or both), treatment (short and long term), and outcome (alive at discharge or death).

Sample size and Statistical analysis: This was a cross-sectional study. A convenient sample of all eligible cases seen during the study period was considered. We analyzed the data with the software IBM SPSS version 20. We have presented continuous variable (age) as median (interquartile range), and discrete variables as frequencies and percentages. A p value $<0.05$ was considered significant for observed differences or associations.

\section{Results}

Patients: During the period of the study, a total of 17703 patients were admitted in the internal medicine and ICU. Of these, 113 patient cases were identified as potential cases of VTE. We excluded 35 cases ( 4 missing files, 22 incomplete files, and 9 diagnoses were changed). A total of 78 case files (about 12 cases seen per year) were retained for this study. This gives an in-hospital prevalence of VTE of 4.4 cases per 1000 admissions (Figure 1).

Descriptive data: Table 1 shows the general characteristics of the study population. There were $42(53.8 \%)$ males and 36 (46.1\%) females. Their ages ranged from 18 to 89 years (median: 53 years [IQR: 40 to 61], $\mathrm{p}=0.81$ between sexes). Of these, 42 were come from home, 27 were referred from other hospitals, and 9 were transferred from other wards to either the ICU or the internal medicine ward. These patients were hospitalized in the internal medicine ward (74 cases) and in the ICU (4 cases).

Outcome data and main results: Figure 2 shows the proportion of VTE. There were $37(47.4 \%)$ cases of DVT, 31 (39.7\%) cases of PE, and 10 (12.8\%) cases of PE associated with DVT.

Table 2 shows the distribution of risk factors of VTE. The most frequent risk factors were-Obesity in 35 (44.9\%) cases, hypertension in 29 (37.2\%) cases, immobility in 16 (20.5\%) cases, and long-haul travel in 14 (17.9\%) cases.

Table 3 shows the clinical presentation of VTE. In PE cases, the most common presentations were dyspnea in 33 (80.48\%) cases, and chest pain in 27 (65.85\%) cases. The most common clinical presentation in the DVT cases was a 


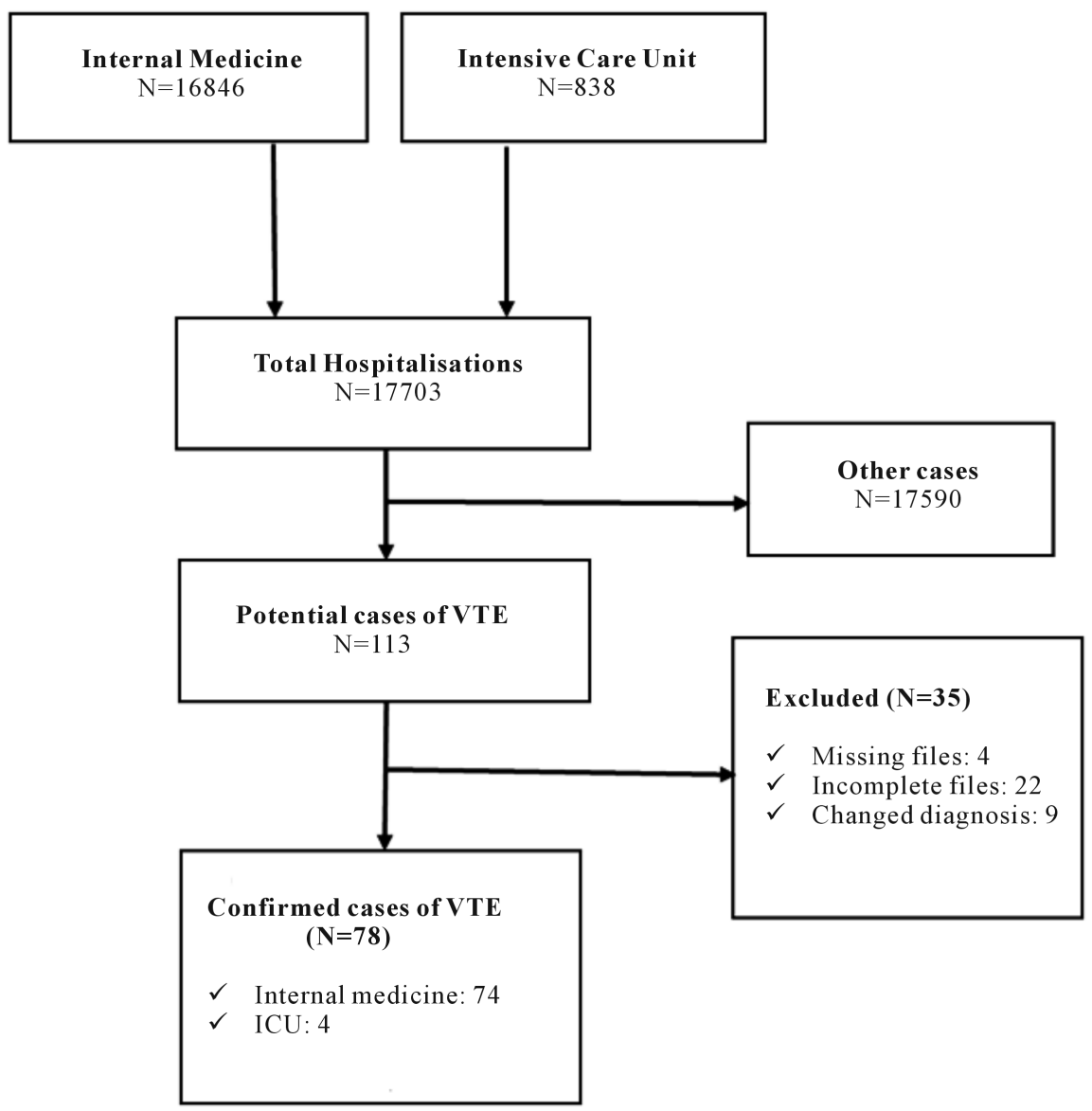

Figure 1. Flow of patients.

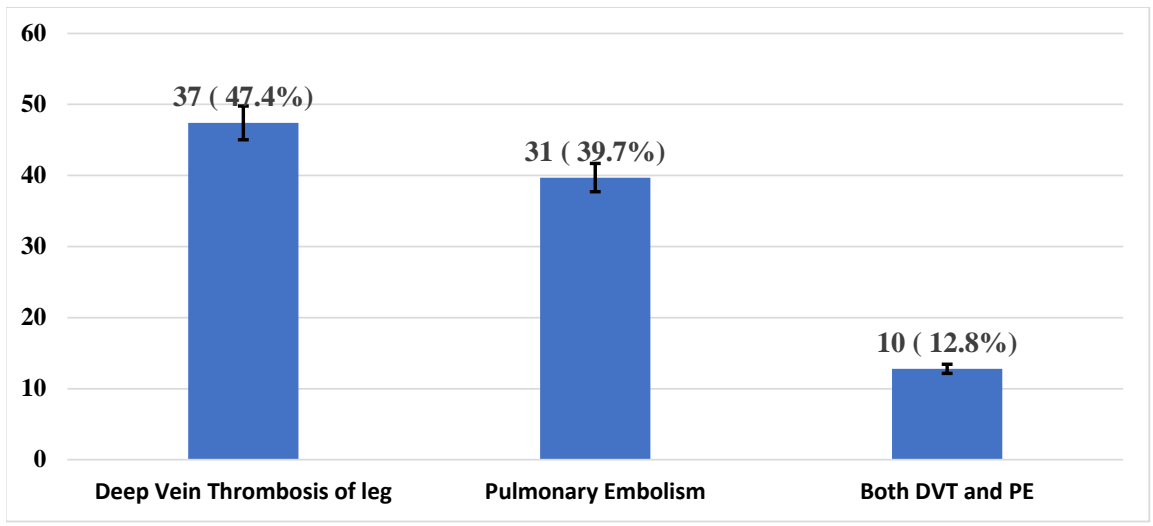

Figure 2. Proportion of VTE in the study population.

swollen inferior limb in $42(89.4 \%)$ cases. In order to confirm the diagnosis of PE, a pulmonary angiography was done in 38 (92.7\%) cases. Endo-luminal defects were present in 36 (94.7\%) cases. There was a parenchymal involvement in $27(71.1 \%)$ cases, with $6(15.8 \%)$ cases of pulmonary infarction, and $6(15.8 \%)$ cases of pleural effusion. In all, 37 ECGs were performed with 29 (78.4\%) being abnormal. The most frequent findings were sinus tachycardia in 19 (51.35\%) cases, anterior T-wave inversion in $13(35.14 \%)$ cases, and S1Q3 pattern in 
Table 1. General characteristics of the study population $(n=78)$.

\begin{tabular}{cc}
\hline \multicolumn{1}{c}{ Variables } & Frequency (\%) \\
\hline Gender & $42(53.8)$ \\
Male & $36(46.2)$ \\
Female & \\
Age Group & $12(15.4)$ \\
$<35$ & $17(21.8)$ \\
$35-44$ & $13(16.7)$ \\
$45-54$ & $20(25.6)$ \\
$55-64$ & $11(14.1)$ \\
$65-74$ & $5(6.5)$ \\
$>75$ & \\
Origin & $42(53.8)$ \\
Home & $27(34.6)$ \\
Referred from other hospitals & $9(11.5)$ \\
Transferred from other wards & \\
Hospitalisation Ward & $74(94.9)$ \\
Internal medicine & $4(5.1)$ \\
Intensive Care Unit &
\end{tabular}

Table 2. Risk factors of venous thrombo-embolism in the study population $(\mathrm{n}=78)$.

\begin{tabular}{lc}
\multicolumn{1}{c}{ Variable } & Frequency (\%) \\
\hline Medical risk factors & $29(37.2)$ \\
Hypertension & $9(11.5)$ \\
Previous VTE & $1(1.3)$ \\
Autoimmune disease & $5(11.5)$ \\
Cancer & $3(3.8)$ \\
Pulmonary tuberculosis & $10(12.8)$ \\
Cardiovascular disease & $11(14.1)$ \\
HIV infection & $3(3.8)$ \\
Dyslipidemia & $4(5.1)$ \\
Central venous catheterization & $15(19.2)$ \\
Others & \\
Recent surgical intervention & $4(5.1)$ \\
Gynecology/obstetrical & \\
Obstetrical & $1(1.3)$ \\
Pregnancy & $2(2.6)$ \\
Puerperium & $1(1.3)$ \\
Abortion & $16(20.5)$ \\
Social risk factors & $8(10.3)$ \\
Exogenous hormones & $35(44.9)$ \\
Immobility & $14(17.9)$ \\
Smoking/toxicomania & $3(3.8)$ \\
Obesity & \\
Long-haul travel ( $\geq 4$ hours) & \\
Family history of VTE & \\
&
\end{tabular}


Table 3. Clinical presentation, electrocardiographic findings, location, and treatment of VTE.

\begin{tabular}{|c|c|}
\hline Variables & Frequency (\%) \\
\hline \multicolumn{2}{|l|}{ Pulmonary Embolism $(n=41)$} \\
\hline Dyspnea & $33(80.5)$ \\
\hline Chest pain & $27(65.9)$ \\
\hline Syncope & $4(9.8)$ \\
\hline Heamoptysis & $3(7.3)$ \\
\hline Respiratory distress & $7(17.1)$ \\
\hline Shock & $2(4.9)$ \\
\hline Right heart failure & $1(2.4)$ \\
\hline Altered state of consciousness & $3(7.3)$ \\
\hline \multicolumn{2}{|l|}{ Deep Vein Thrombosis $(n=47)$} \\
\hline Calf stiffness & $21(44.7)$ \\
\hline Homanns sign & $24(51.1)$ \\
\hline Pain & $37(78.7)$ \\
\hline Inferior limb swelling & $42(89.4)$ \\
\hline \multicolumn{2}{|l|}{ Electrocardiogram $(n=37)$} \\
\hline Right Ventricular hypertrophy & $1(2.4)$ \\
\hline Incomplete right bundle branch block & $5(12.2)$ \\
\hline $\mathrm{S}_{1} \mathrm{Q}_{3}$ pattern & $11(26.8)$ \\
\hline Anterior T-wave inversion & $13(31.7)$ \\
\hline Tachycardia & $19(46.3)$ \\
\hline \multicolumn{2}{|l|}{ Echography of leg Veins $(n=47)$} \\
\hline Proximal location only & $25(53.2)$ \\
\hline External iliac vein & $2(4.3)$ \\
\hline Femoral vein & $6(12.8)$ \\
\hline Ilio-femoral vein & $5(10.6)$ \\
\hline Popliteal vein & $8(17)$ \\
\hline Ilio-femoro-popliteal vein & $1(2.1)$ \\
\hline Popliteo-femoral vein & $18(38.3)$ \\
\hline Distal location only & $4(8.5)$ \\
\hline Sural vein & $17(36.1)$ \\
\hline Peroneal vein & $2(4.3)$ \\
\hline Posterior tibial vein & $1(2.1)$ \\
\hline Both Distal and proximal locations & $16(34)$ \\
\hline \multicolumn{2}{|l|}{ Venous Thrombo-Embolism Treatment $(n=78)$} \\
\hline Low Melecular Weight Heparin & $73(93.6)$ \\
\hline Vitamin $\mathrm{K}$ antagonists & $62(79.5)$ \\
\hline Unfractioned heparin & $8(10.3)$ \\
\hline New oral anticoagulants & $1(1.3)$ \\
\hline Elastic compressive stockings & $15(19.2)$ \\
\hline Patient education & $21(26.9)$ \\
\hline
\end{tabular}


11 cases $(29.73 \%)$. DVT cases were all confirmed by compression ultrasounds performed on all 47 cases, which showed the locations of the thrombi. On establishment of a diagnosis, patients were placed on treatment. These treatments included unfractionated heparins, Low-Molecular-Weight Heparin (LMWH), and vitamin $\mathrm{K}$ antagonists. New oral anticoagulant was used in a one case. Thrombolysis and embolectomy were not used as means of treatment. The duration of hospitalization ranged from 1 to 36 days (median: 11days [IQR: 8 - 16]).

Figure 3 shows the short term mortality of VTE. There were $8(10.3 \%)$ cases of death. This was highest in those with PE. A secondary pulmonary infection occurred in $6(14.6 \%)$ cases of PE. Of these 8 fatal cases, 2 had a DVT associated with: advanced age (71years), hypertension and a severe sepsis in one case, and a thrombosis of the inferior vena cava with a military tuberculosis in the other. In the other 6 cases, 5 had PE, and 1 had a PE associated with DVT. In these 6 cases, the association of risk factors was advanced age, HIV infection cigarette smoking; advanced age, hypertension, recent surgery; advanced age, hypertension, obesity; surgery, immobility, sepsis; advanced age and cancer; and finally, advanced age and hypertension.

\section{Discussion}

The objective of this cross-sectional descriptive study was to describe the epidemiology, clinical presentations, and outcome of VTE at the Douala General Hospital (DGH). VTE was seen in 4.4 cases per 1000 admissions in the internal medicine unit and ICU. About twelve cases of VTE are seen yearly at the DGH, with an in-hospital mortality of ten percent. Obesity and hypertension were the main risk factors, with dyspnea and chest pain being the main clinical manifestations in PE, and lower limb swelling the main symptom in DVT.

The male predominance this study is similar to the $55 \%$ reported by Kingue et al. in Yaoundé-Cameroon [17], and different from that reported by that reported by Ogeng'o et al. at an East African tertiary referral hospital [6]. The mean age of or patients was lower than the $60 \pm 11.7$ years reported by Aissa

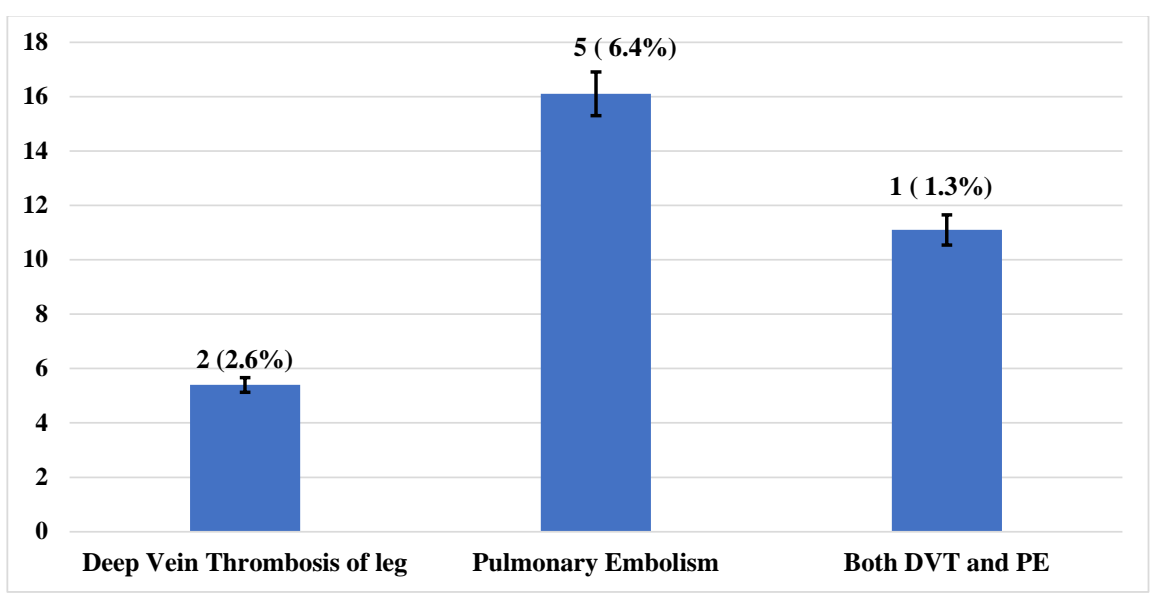

Figure 3. Short term mortality according to the type of VTE. 
et al. [7] in Tunisia, but higher that reported by Kingue et al. [17] and Ogengo'o et al. [6], who reported a mean age of 46 and 40.8 years respectively.

The most frequent risk factors of a VTE in this study were morbid obesity (44.9\%), hypertension (37.2\%), immobility (20.5\%), long-haul travel (17.9\%) and HIV infection (14.1\%). These results were partly similar to those obtained by Ogeng'o et al. who reported as main risk factors DVT, hypertension, pulmonary tuberculosis, HIV infection, puerperium, diabetes mellitus and cigarette smoking [6], Kingue et al. who had as main risk factors surgery, history of VTE and morbid obesity [17]. Sotumbi et al. reported as risk factors hypertension, phlebitis, chronic cor Pulmonale, and heart failure [3]. In India, Lee et al. had as main risk factors malignancy and post-operative status [13]. Yamada et al. in Japan had as main risk factors; female gender, prolonged immobilization, history of prior VTE, lower extremity varicose veins, BMI $\geq 25 \mathrm{~kg} / \mathrm{m}^{2}$, extremity paralysis and gout/hyperuricemia [18]. Ishida et al. reported as risk factors for PE, advanced age, DVT, cancer, fracture, obesity and surgery [19]. The differences observed in the predominance of the risk factors can be explained by the fact that a prophylactic VTE treatment is given to cases with predisposing factors such as surgery, phlebitis and heart failure thus reducing the occurrence of VTE in these patients at the Douala General hospital. The different lifestyles, diets and disease predominance in these different populations can also be a cause of the difference in frequencies of the different risk factors of VTE observed.

In this study, the most recurrent clinical presentation of a PE was a dyspnea and chest pain. This was similar to Igun et al. who reported severe dyspnea and central chest pain as main clinical presentation, associated to loss of consciousness, hemoptysis, and mental confusion [20]. Sotunmbi et al. in Bamako had respiratory distress, hemoptysis, syncope and circulatory collapse as clinical presentation [3]. In Pakistan, PE presented with tachypnea and tachycardia. These differences in clinical presentations may be due to the different severities of the disease on admission at the different health institutions. In the case of DVT, our results and those of Igun et al. [20] were similar, with the most common clinical feature being limb swelling.

The in-hospital mortality rate during a VTE was $10 \%$. Sotunmbi et al., Husain et al., and Lee et al. [3] [13] [19] reported similar results with respective mortality rates of $11.3 \%, 13 \%$ and $13.5 \%$. This was lower than that reported by Kingue et al. who had a $16.6 \%$ death rate [17].

\section{Limitations}

The main limitation of this study is the retrospective collection of data. This led to many case files being excluded because of missing key data. The result is a reduction in the power of the study, and alterations in the true in-hospital prevalence of VTE, its risk factors, and the outcome rate. This also, did not permit us to the study the incidence of VTE, which can only be assessed in Cohort studies. 


\section{Conclusion}

The objective of this cross-sectional descriptive study was to describe the epidemiology, clinical presentations, and outcome of VTE at the Douala General Hospital (DGH). VTE was seen in 4.4 cases per 1000 admissions in the internal medicine unit and ICU. About twelve cases of VTE are seen yearly at the DGH, with an in-hospital mortality of ten percent. Obesity and hypertension were the main risk factors, with dyspnea and chest pain being the main clinical manifestations in PE, and lower limb swelling the main symptom in DVT.

\section{Disclosure}

None to declare.

\section{Funding}

None.

\section{Authors' Contributions}

Study conception: FK, BH, MSD, HL, and BHMN. Study design: FK, BH, AD, MSD, HL, BHMN. Data collection: FK, BH, AM, JFK, CK, MSD, MS, HN, AC, SM, YW, RH, AK. Data analysis and Interpretation: AM, AMJ, FK, HL, BH, AD, YW, and MSD. Drafting of the manuscript: FK, BH, AM, AMJ, JFK, CK, SM, $\mathrm{HN}, \mathrm{RH}, \mathrm{AK}$. All the authors have read and approved of the final draft for publication.

\section{Acknowledgements}

We thank the nursing staff of the Internal Medicine and the Intensive Care Unit of the DGH for helping with retrieving the patient records.

\section{References}

[1] Beckman, M.G., Hooper, W.C., Critchley, S.E. and Ortel, T.L. (2010) Venous Thromboembolism: A Public Health Concern. American Journal of Preventive Medicine, 38, S495-S501. https://doi.org/10.1016/j.amepre.2009.12.017

[2] Cohen, A.T., Agnelli, G., Anderson, F.A., Arcelus, J.I., Berggvist, D., Bretch, J.G., et al. (2007) Venous Thromboembolism (VTE) in Europe. The Number of VTE Events and Associated Morbidity and Mortality. Thrombosis and Haemostasis, 98, 756-764.

[3] Sotunmbi, P.T., Idowu, A.T., Akang, E.E. and Aken'Ova, Y.A. (2006) Prevalence of Venous Thromboembolism at Post-Mortem in an African Population: A Cause for Concern. African Journal of Medicine and Medical Sciences, 35, 345-348.

[4] Awotedu, A.A., Igbokwe, E.O., Akang, E.E. and Aghadiuno, P.O. (1992) Pulmonaryembolism in Ibadan, Nigeria: Five Years Autopsy Report. Central African Journal of Medicine, 38, 432-435.

[5] Elegbeleye, O.O. and Femi-Pearse, D. (1975) Pulmonaryembolism in Africans. Tropical and Geographical Medicine, 27, 31-33.

[6] Ogeng'o, J.A., Obimbo, M.M., Olabu, B.O., Gatonga, P.M. and Ong'era, D. (2011) 
Pulmonary Thromboembolismin an East African Tertiary Referral Hospital. Journal of Thrombosis and Thrombolysis, 32, 386-391. https://doi.org/10.1007/s11239-011-0607-4

[7] Aissa, I., Rachdi, I., Ben Miled, K. and Ghedira, H. (2011) Incidence de la maladie thromboembolique veineuse chez des hommes admis dans un service de pneumologie pour affection respiratoire aiguë. Revue de Pneumologie Clinique, 67, 129-135. https://doi.org/10.1016/j.pneumo.2010.04.003

[8] Touze, J.E., Moncany, G., Amonkou, A., Cailleau, G., Monnier, A., Kacou, M., et al. (1985) La maladie thrombo-embolique pulmonaire en Côte d'Ivoire. A propos de 13 cas. Medecine Tropicale (Mars), 45, 43-46.

[9] Hantous-Zannad, S., Esseghaier, S., Ridène, I., Zidi, A., Ben Romdhane, K., Baccouche, I., et al. (2010) Acute Pulmonary Embolism: Epidemiologic and Tomodensitometric Study. Tunis Med., 88, 880-884.

[10] Angral, R., Islam, M.S. and Kundan, S. (2012) Incidence of Deep Vein Thrombosis and Justification of Chemoprophylaxis in Indian Patients: A Prospective Study.

Bangladesh Medical Research Council Bulletin, 38, 67-71.

https://doi.org/10.3329/bmrcb.v38i2.12885

[11] Taniguchi, S., Fukuda, I., Daitoku, K., Minakawa, M., Odagiri, S., Suzuki, Y., et al. (2009) Prevalence of Venous Thromboembolism in Neurosurgical Patients. Heart Vessels, 24, 425-428. https://doi.org/10.1007/s00380-008-1135-9

[12] Molina, J.A., Jiang, Z.G., Heng, B.H. and Ong, B.K. (2009) Venous Thromboembolism at the National Health Care Group, Singapore. ANNALS Academy of Medicine Singapore, 38, 470-478.

[13] Lee, A.D., Stephen, E., Agarwal, S. and Premkumar, P. (2009) Venous Thrombo-Embolism in India. European Journal of Vascular and Endovascular Surgery, 37, 482-485. https://doi.org/10.1016/j.ejvs.2008.11.031

[14] Choi, W.I., Lee, M.Y., Oh, D., Rho, B.H. and Hales, C.A. (2011) Estimated Incidence of Acute Pulmonary Embolismin a Korean Hospital. Clinical and Applied Thrombosis/ Hemostasis, 17, 297-301. https://doi.org/10.1177/1076029610368669

[15] Yang, Y., Liang, L., Zhai, Z., He, H., Xie, W., Peng, X., et al. (2011) Investigators for National Cooperative Project for Prevention and Treatment of PTE-DVT. Pulmonary Embolism Incidence and Fatality Trends in Chinese Hospitals from 1997 to 2008: A Multicenter Registration Study. PLoS ONE, 6, e26861. https://doi.org/10.1371/journal.pone.0026861

[16] Macklon, N.S. and Greer, I.A. (1996) Venous Thromboembolic Disease in Obstetrics and Gynaecology: The Scottish Experience. Scottish Medical Journal, 41, 83-86. https://doi.org/10.1177/003693309604100305

[17] Kingue, S., Tagny-Zukman, D., Binam, F., Nouedoui, C., Teyang, A. and Muna, W.F. (2002) La maladie thrombo-embolique veineuse au Cameroun (à propos de 18 cas). Medecine Tropicale, 62, 47-50.

[18] Yamada, N., Ota, S., Liu, Y., Crane, M.M., Chang, C.M., Thanker, S., et al. (2010) Risk Factors for Nonfatal Pulmonary Embolism in a Japanese Population: A Hospital-Based Case-Control Study. Angiology, 61, 269-274. https://doi.org/10.1177/0003319709335907

[19] Ishida, K. and Masuda, M. (2007) Review of Acute Pulmonary Embolismin a General Hospital. Surgery Today, 37, 740-744. https://doi.org/10.1007/s00595-006-3496-y

[20] Igun, G.O. (2001) A 10-Year Review of Venous Thrombo-Embolism in Surgical Patients Seen in Jos Nigeria. Nigerian Postgraduate Medical Journal, 8, 69-73. 